\title{
A review of selective hypothermia in the management of traumatic brain injury
}

\author{
Eisha Christian, B.A., ${ }^{1}$ Gabriel Zada, M.D., ${ }^{1}$ Gene Sung, M.D., ${ }^{2}$ \\ and Steven L. Giannotta, M.D. ${ }^{1}$ \\ Departments of ${ }^{1}$ Neurosurgery and ${ }^{2}$ Neurology, Keck School of Medicine, \\ University of Southern California, Los Angeles, California
}

\begin{abstract}
Object. Traumatic brain injury (TBI) remains a significant cause of morbidity and death in the US and worldwide. Resuscitative systemic hypothermia following TBI has been established as an effective neuroprotective treatment in multiple studies in animals and humans, although this intervention carries with it a significant risk profile as well. Selective, or preferential, methods of inducing cerebral hypothermia have taken precedence over the past few years in order to minimize systemic adverse effects. In this report, the authors explore the current methods available for inducing selective cerebral hypothermia following TBI and review the literature regarding the results of animal and human trials in which these methods have been implemented.

Methods. A search of the PubMed archive (National Library of Medicine) and the reference lists of all relevant articles was conducted to identify all animal and human studies pertaining to the use of selective brain cooling, selective hypothermia, preferential hypothermia, or regional hypothermia following TBI.

Results. Multiple methods of inducing selective cerebral hypothermia are currently in the experimental phases, including surface cooling, intranasal selective hypothermia, transarterial or transvenous endovascular cooling, extraluminal vascular cooling, and epidural cerebral cooling.

Conclusions. Several methods of conferring preferential neuroprotection via selective hypothermia currently are being tested. Class I prospective clinical trials are required to assess the safety and efficacy of these methods.

(DOI: 10.3171/FOC.2008.25.10.E9)
\end{abstract}

\section{KEY WORDS • hypothermia - intracranial pressure - neuroprotection • selective brain cooling - traumatic brain injury}

$\mathrm{T}$ RAUMATIC brain injury remains a significant cause of morbidity and death in the US and worldwide. The Centers for Disease Control and Prevention estimates that at least 5.3 million Americans, or $~ 2 \%$ of the US population, currently have a long-term or lifelong need for help to perform activities of daily living as a result of a TBI. ${ }^{38}$ Current nonsurgical treatment strategies following TBI consist primarily of ICP management and cardiopulmonary support measures. Although resuscitative hypothermia was initially described as early as $1897^{32}$ and has been established as an effective method of neuroprotection in multiple animal studies, ${ }^{2,7,16}$ clinical trials in humans following TBI have been extremely limited until only recently. The multifaceted benefits offered by hypothermic management in achieving neuroprotection, including reductions in the cerebral metabolic rate, ${ }^{14,22}$ inflammatory response activity, ${ }^{40}$ epileptic discharges,,${ }^{35}$

Abbreviations used in this paper: GOS = Glasgow Outcome Scale; ICP = intracranial pressure; $\mathrm{MCA}=$ middle cerebral artery; $\mathrm{RCT}=$ randomized clinical trial; $\mathrm{SBC}=$ selective brain cooling; $\mathrm{TBI}=$ traumatic brain injury. and the production of reactive oxygen species, ${ }^{26}$ have supported its role as a potent therapeutic agent in preventing secondary injury associated with $\mathrm{TBI}^{3}{ }^{3}$

Results of clinical trials in which authors have implemented systemic hypothermia in humans following TBI have been less definitive, with some studies revealing improved neurological outcomes ${ }^{15,21,28,31}$ and others demonstrating more equivocal results. ${ }^{8,20}$ Questions regarding patient selection, methods of instituting hypothermia, induction time, depth and extent of hypothermia, and rewarming strategies have been raised as potential factors limiting the observable benefit of this intervention. In many studies, the benefits derived from systemic hypothermia have been offset by appreciable increases in the rates of adverse outcomes. ${ }^{24}$ The most frequent risks associated with systemic hypothermia include cardiovascular and pulmonary complications, infections, and increased rates of thrombocytopenia. ${ }^{8,20,31,34}$ Additional adverse effects have been associated with the rewarming period following induction of systemic hypothermia and have included severe infections and shock. ${ }^{25}$ Given the lack of a clear risk/benefit profile, the Brain Trauma Foundation and the American Association of Neurologi- 


\section{E. Christian et al.}

TABLE 1: Prospective RCTs in which selective hypothermia was assessed in patients with TBI*

\begin{tabular}{|c|c|c|c|c|c|c|c|c|}
\hline $\begin{array}{l}\text { Authors } \\
\& \text { Year }\end{array}$ & $\begin{array}{l}\text { Method of } \\
\text { Hypothermia }\end{array}$ & $\begin{array}{l}\text { No. } \\
\text { of } \mathrm{Pa}- \\
\text { tients }\end{array}$ & $\begin{array}{c}\text { Initiation of } \\
\text { Treatment } \\
\text { Post-TBI }\end{array}$ & $\begin{array}{c}\text { Target } \\
\text { Cooling } \\
\text { Temp }\left({ }^{\circ} \mathrm{C}\right)\end{array}$ & $\begin{array}{l}\text { Cooling } \\
\text { Duration } \\
\text { (hrs) }\end{array}$ & $\begin{array}{c}\text { Comparison } \\
\text { Groups }\end{array}$ & Key Findings & Neurological Outcome \\
\hline $\begin{array}{l}\text { Wang et } \\
\text { al., } 2004\end{array}$ & cooling helmet & 16 & $<24 \mathrm{hrs}$ & 33 & $48-72$ & $\begin{array}{l}\text { cooling helmet vs } \\
\text { no hypothermia }\end{array}$ & $\begin{array}{l}3.4 \text { hours to achieve } \\
\text { brain temp of } 34^{\circ} \mathrm{C} ; 6.7 \\
\text { hrs to reach change in } \\
\text { systemic temperature }\end{array}$ & NA \\
\hline $\begin{array}{l}\text { Andrews et } \\
\text { al., } 2005\end{array}$ & intranasal air & 15 & $0-5$ days & NA & 6 & $\begin{array}{l}\text { intranasal air vs } \\
\text { no hypothermia }\end{array}$ & $\begin{array}{l}\text { no difference in temp } \\
\text { reduction }\end{array}$ & NA \\
\hline $\begin{array}{l}\text { Qiu et al., } \\
2006\end{array}$ & $\begin{array}{l}\text { cooling cap + } \\
\text { neckband }\end{array}$ & 90 & on admission & $33-35$ & 72 & $\begin{array}{l}\text { cooling cap vs no } \\
\text { hypothermia }\end{array}$ & $\begin{array}{l}\text { decreased ICPs at } 24 \text {, } \\
48, \& 72 \text { hrs in hypo- } \\
\text { thermia group }\end{array}$ & $\begin{array}{l}\text { GOS Score } 4 \text { or } 5 \text { at } \\
6 \text {-mo FU in } 68.9 \% \text { of } \\
\text { hypothermia group } \\
\text { vs } 46.7 \% \text { of controls; } \\
p<0.05\end{array}$ \\
\hline $\begin{array}{l}\text { Liu et al., } \\
2006\end{array}$ & $\begin{array}{l}\text { cooling cap + } \\
\text { neckband }\end{array}$ & 66 & on admission & $33-35$ & 72 & $\begin{array}{l}\text { cooling cap vs } \\
\text { mild systemic } \\
\text { hypothermia vs no } \\
\text { hypothermia }\end{array}$ & $\begin{array}{l}\text { decreased ICPs at } 24 \text {, } \\
48, \& 72 \mathrm{hrs;} \\
\text { increase in serum su- } \\
\text { peroxide dismutase in } \\
\text { hypothermia group on } \\
\text { Days } 3 \& 7 \text { after injury }\end{array}$ & $\begin{array}{l}\text { GOS Score } 4 \text { or } 5 \text { at } \\
2-y r \text { FU in } \\
72.7 \% \text { of cooling cap } \\
\text { group vs } 57.1 \% \text { of } \\
\text { systemic group vs } \\
34.8 \% \text { of controls; } \\
\text { p<0.05 }\end{array}$ \\
\hline $\begin{array}{l}\text { Harris et } \\
\text { al., } 2007\end{array}$ & $\begin{array}{l}\text { intranasal air } \\
(+\mathrm{NO})+\text { head } \\
\text { fanning }\end{array}$ & 12 & NA & NA & 6 & $\begin{array}{l}\text { airflow alone vs } \\
\text { fanning alone vs } \\
\text { airflow + fanning } \\
\text { vs } \\
\text { neither interven- } \\
\text { tion }\end{array}$ & $\begin{array}{l}\text { reduction in brain temp } \\
\text { of } 0.31^{\circ} \mathrm{C} \text { w/in } 5 \mathrm{~min}\end{array}$ & NA \\
\hline
\end{tabular}

* $\mathrm{FU}=$ follow-up; $\mathrm{NA}=$ not available; Temp = temperature.

cal Surgeon have issued a Level III recommendation for the optional and cautious use of hypothermia in adults with TBI. ${ }^{4}$

Several investigators have postulated that the administration of selective, or preferential, cerebral hypothermia following TBI may confer the same neuroprotective benefits as systemic hypothermia, while reducing the associated risks. Furthermore, the induction time for selective hypothermia may be shorter, thus providing earlier neuroprotection from secondary injury following TBI. In this report, we examine the currently available methods for implementing selective cerebral hypothermia in patients following TBI and review the literature regarding the results of animal and human trials in which these methods have been applied.

\section{Methods}

A search of PubMed (National Library of Medicine) and the reference lists of all relevant articles was conducted to identify all animal and human studies pertaining to the use of SBC, selective hypothermia, preferential hypothermia, or regional hypothermia following TBI. A database was created and subsequently reviewed (Table 1).

\section{Results}

Surface Cooling

Surface cooling remains the simplest method of inducing selective hypothermia. Basic methods of systemic hypothermia via surface cooling have been refined to achieve regional cooling of the cranial contents. These methods have traditionally included ice packs, ice baths, and head fanning, although more complex means such as cooling helmets and caps have been used more recently.

In 2004, Wang et al. ${ }^{41}$ reported the results of a RCT on the safety and efficacy of a cooling helmet first developed based on National Aeronautics and Space Administration (NASA) technology. This device has 2 components: a head/neck liner and a conditioning unit. The liner is made from a lightweight, thin, urethane-laminated nylon with 2 layers consisting of a liquid cooling heat exchanger and a pressurizable air bladder. The liner has bilateral frontal openings and an anterior midline neck opening for urgent cranial and tracheal access. The conditioning unit serves as an insulated ice reservoir system that can be operated with either a standard power supply or batteries. The study by Wang and colleagues included patients with severe stroke or TBI and excluded those with systemic diseases, cervical spine injuries, and significant head lacerations. The study protocol was initiated within 
24 hours of admission, and patients were randomized to a cooling helmet or no hypothermia intervention. Cerebral and systemic temperatures in both patient groups were monitored for 72 hours after admission. The cooling helmet provided a mean change in the brain-body temperature of $-1.6^{\circ} \mathrm{C}$, as opposed to a change of $+0.22^{\circ} \mathrm{C}$ in the control group $(\mathrm{p}<0.0001)$. Results showed an average reduction of $1.84^{\circ} \mathrm{C}$ in the hypothermia group within 1 hour of treatment application, with an average 3.4 hours (range 2-6 hours) to achieve a brain temperature $<34^{\circ} \mathrm{C}$. Moreover, an average of 6.7 hours (range 1-12 hours) elapsed prior to any decrease in systemic temperature. No significant complications were reported, although there was 1 episode of asymptomatic bradycardia that resolved after raising the core body temperature by $0.5^{\circ} \mathrm{C}$. The main conclusion of their study underlined the practicality of this method in inducing rapid SBC, its relatively low risk profile, and the delayed onset of systemic hypothermia. Note, however, that no outcome benefits were studied in this preliminary trial.

In 2006, Liu et al. ${ }^{25}$ described a preliminary RCT in which they compared SBC with mild systemic hypothermia and normothermia. Selective brain cooling to $33-35^{\circ} \mathrm{C}$ was induced via a cooling helmet and neckband, whereas systemic hypothermia to $33-35^{\circ} \mathrm{C}$ (rectal temperature) was achieved using a cooling blanket. The cooling helmet consisted of circulating saline at $4^{\circ} \mathrm{C}$, and a neckband containing blue ice strips was placed around the neck. Treatment was performed for up to 6 hours/ day for the first 3 days following injury. Natural rewarming began on the 3rd day after injury. The mean nadir brain temperatures were significantly lower $\left(33^{\circ} \mathrm{C}\right)$ after SBC compared with those following mild systemic hypothermia $\left(35^{\circ} \mathrm{C}\right)$. The authors reported lower ICPs in the SBC group compared with those in controls. Furthermore, systemic levels of superoxide dismutase measured on postinjury Days 3 and 7 were higher in the SBC and mild systemic hypothermia groups compared with those in the control group. Finally, survival rates and the proportions of patients with good neurological outcomes (GOS Score 4 or 5) were significantly improved in the SBC group versus the systemic hypothermia and control groups $(\mathrm{p}<0.05)$. There were no significant differences in complication rates (infections, thrombocytopenia, or cardiovascular complications) among the 3 groups.

In another study by Qiu et al., ${ }^{33} 90$ patients that suffered a TBI were randomized to a selective hypothermia group (a cooling headcap and neckband) or a control group (no intervention). Brain temperatures of $33-35^{\circ} \mathrm{C}$ were maintained for 3 days after injury. No increased complication rate was noted in the selective hypothermia group. Furthermore, the authors reported statistically significant decreases in ICPs at 24, 48, and 72 hours in the hypothermia group. Improved neurological outcomes were reported in the treatment group at 6 months following injury, with good neurological outcomes (GOS Score 4 or 5 ) in $68.9 \%$ of the hypothermia group and $46.7 \%$ of the control group $(\mathrm{p}<0.05)$.

Selective surface cooling has established Class I evidence supporting its use in the management of neonatal encephalopathy. ${ }^{17}$ Per initial studies, surface cool- ing methods applied for several hours a day for the first 3 days after injury appear to be a safe and noninvasive method of implementing regional hypothermia. However, more Class I evidence is required to corroborate these results. The availability of the cooling helmet and circulating hypothermia machine remains an issue of practicality at this time.

\section{Intranasal SBC}

Intranasal cooling of the cranial contents appears to be a promising treatment following TBI. Several methods of cooling the brain via the nasopharynx have been attempted in animals; only a few human clinical trials have been completed to date. In a small RCT authors attempted room temperature airflow through the upper respiratory tract of intubated brain-injured patients but demonstrated no benefit in the reduction of brain temperature associated with this method. ${ }^{1}$ In a follow-up study, the same authors attempted nasal airflow with supplemental NO as well as bilateral head fanning in a group of 12 patients. In this study, a mild, statistically significant decrease of $0.31{ }^{\circ} \mathrm{C}$ in brain temperature was observed within $5 \mathrm{~min}$ utes in the selective hypothermia group. ${ }^{19}$ The authors concluded that heat loss from the upper airways and the skull base can reduce parenchymal brain temperature in brain-injured humans in a rapid, controlled fashion.

Covaciu and associates ${ }^{13}$ reported their results for the intranasal placement of balloon catheters filled with chilled, circulating saline. Hypothermia was maintained for 6 hours in a porcine model via this method. No major disturbances in systemic circulation or physiological variables were associated with the intranasal cooling. There was a rapid decrease in cerebral temperature within the first 20 minutes of inducing hypothermia and a mean reduction of $2.8^{\circ} \mathrm{C}$ in cerebral temperature to a target temperature of $35^{\circ} \mathrm{C}$. In comparison, the systemic temperature decreased by a mean of $1.7^{\circ} \mathrm{C}$.

More recently, BeneChill, Inc., has developed the RhinoChill System, an intranasal device that sprays an inert evaporative coolant onto the surfaces of the upper airways and skull base via nasal prongs (Fig. 1). The only major contraindication at this time in patients with TBI is the presence of skull base fractures. The liquid coolant is contained in bottles that can be stored at room temperature. It is sprayed into the nasal cavity and disperses widely because of its low surface tension. Once in contact with the nasopharynx, the coolant rapidly evaporates. Heat dissipates through the skull base via conductive mechanisms, and cooled blood along the skull base spreads via the arteries to the remainder of the brain (Fig. 2). The intranasal temperature is $\sim 2^{\circ} \mathrm{C}$. In a sheep trial, the RhinoChill device was compared with wholebody surface cooling. ${ }^{44}$ In that study, brain cooling was significantly faster with the RhinoChill device than with systemic hypothermia. Furthermore, brain-to-systemic temperature gradients were maintained, and the brain therapeutic hypothermia zone (defined as $\leq 3.5^{\circ} \mathrm{C}$ below baseline) was reached within 15 minutes. There were no complications associated with this method. In additional studies, the RhinoChill device significantly improved resuscitation rates as well as survival and neurological out- 


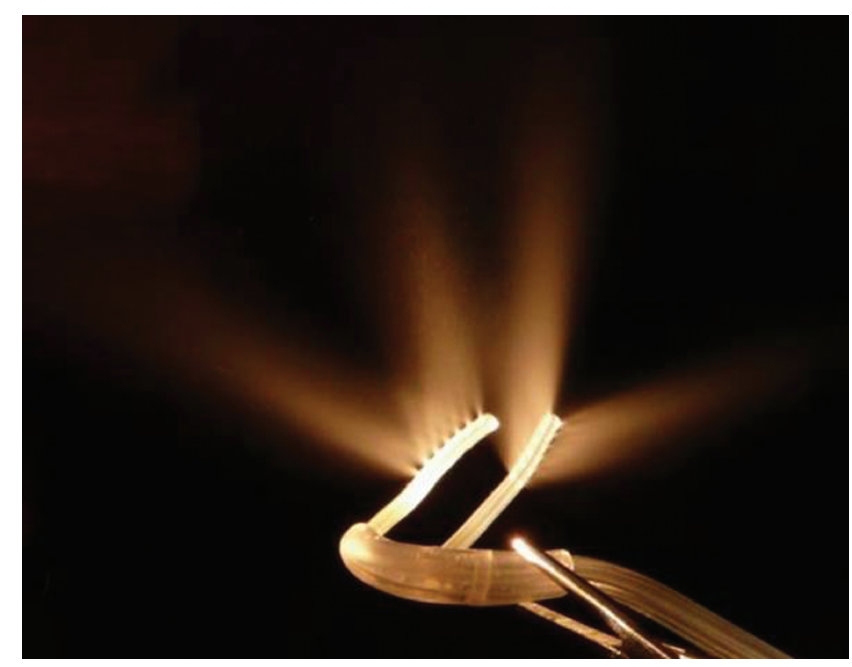

FIG. 1. Image showing the nasal prong system of the RhinoChill device, which is inserted into the nasal cavity and sprays an evaporative perfluorocarbon coolant that cools the skull base. Reprinted with permission from BeneChill, Inc.

comes in pigs undergoing cardiopulmonary resuscitation following induced ventricular fibrillation. ${ }^{39}$

Intranasal selective hypothermia appears to be a relatively noninvasive and rapid method of achieving preferential hypothermia with minimal systemic disturbances. Multiple institutions, including our own, are currently enrolling patients into prospective clinical trials to assess the safety and efficacy of the RhinoChill device.

\section{Endovascular Cooling}

The infusion of cold saline or blood has been attempted via a transvenous or transarterial route to achieve selective cooling of the brain. The first description of selective hypothermia via the carotid arteries appeared in 1954; Parkins and associates ${ }^{30}$ reported the unilateral perfusion of the common carotid artery in dogs (Fig. 3). During a period of complete circulatory occlusion, blood was drawn from the carotid artery, cooled extracorporeally, and reinfused into the carotid artery. The authors were able to achieve cerebral temperatures of $15^{\circ} \mathrm{C}$ while maintaining systemic temperatures of $32^{\circ} \mathrm{C}$. Significant neuronal injury occurred at brain temperatures below $12^{\circ} \mathrm{C}$, but neuroprotective effects were noted in the range of $15-20^{\circ} \mathrm{C}$. In 1992 Ohta et al. ${ }^{29}$ successfully perfused cold lactated Ringer solution via the vertebral artery in dogs while clamping both carotid arteries and reported the maintenance of temperatures of $27-28^{\circ} \mathrm{C}$ and a mean systemic temperature of $33.9^{\circ} \mathrm{C}$ for up to 60 minutes. They reported improved neurological outcomes in the hypothermia group compared with those in the normothermic infusion control group, in which no animals survived. No histological evidence of ischemia was observed in the hypothermia group.

In 1996 Schwartz et al. ${ }^{36}$ attempted perfusion of cold autologous blood via the common carotid artery in baboons. Blood was drawn from a femoral access catheter, cooled in an extracorporeal fashion, and pumped back into the common carotid artery at systemic blood

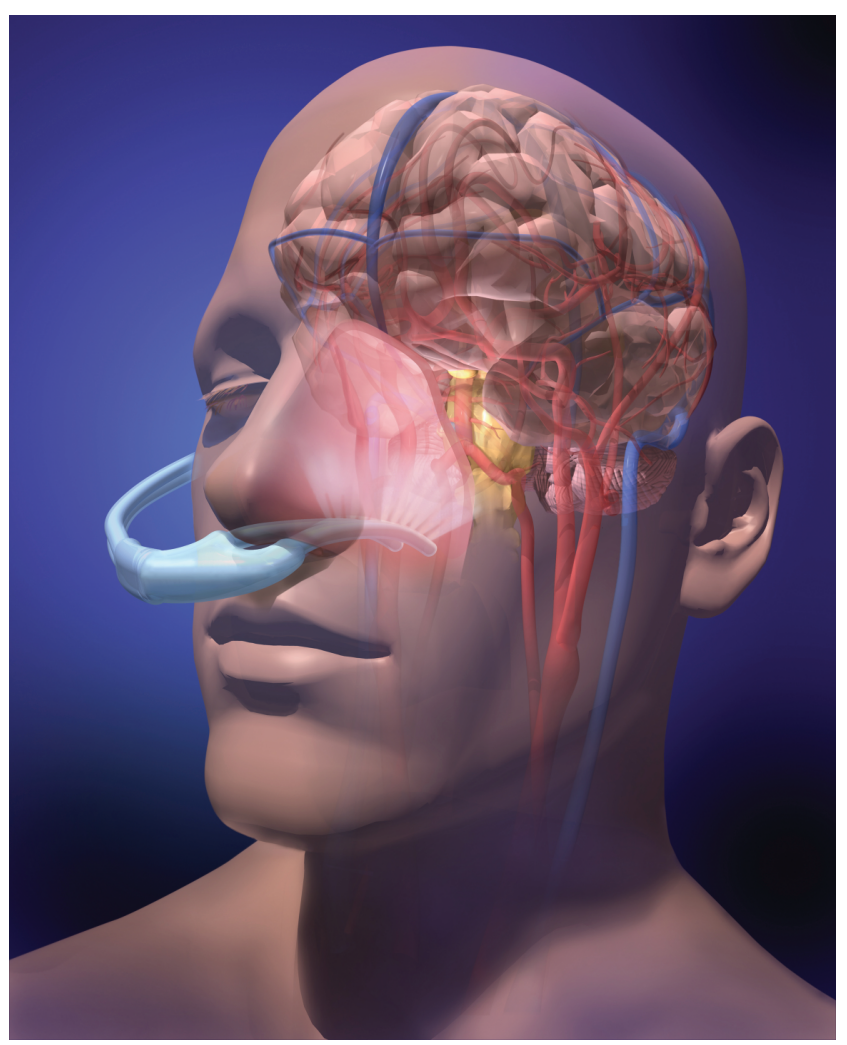

FIG. 2. Image depicting the method of action of the RhinoChill device. Once the coolant is sprayed into the nasal cavity, it rapidly evaporates. Heat dissipates through the skull base via conductive mechanisms, and cooled blood along the skull base spreads via the arteries to the remainder of the brain. Reprinted with permission from BeneChill, Inc.

pressure. They were able to cool the brain to as low as $18-19^{\circ} \mathrm{C}$ within a mean time of $26 \pm 13$ minutes, with systemic temperatures stabilizing at an average of $34^{\circ} \mathrm{C} .{ }^{36}$ This same study demonstrated decreases in cerebral blood flow associated with the selective hypothermia treatment and no resulting hemodynamic complications. In 2006, Jiang and colleagues ${ }^{22}$ described the perfusion of cold lactated Ringer solution $\left(5^{\circ} \mathrm{C}\right)$ versus normothermic lactated Ringer solution $\left(37^{\circ} \mathrm{C}\right)$ via the internal carotid artery following cerebral ischemia in Rhesus monkeys. Global cerebral hypothermia was induced in the treatment group to as low as $15-16^{\circ} \mathrm{C}$, with minimal changes in systemic temperature. Normal neurological function was reported in the hypothermia group, compared with death in all animals in the normothermia group. Furthermore, no histological evidence of ischemia was noted in the hypothermia group, compared with the finding of medullary necrosis in the normothermia group.

In 2005 , Wen et al. ${ }^{43}$ performed a feasibility experiment assessing hypothermic retrograde jugular flush as an alternative to carotid artery infusion. The external jugular veins of rats were cannulated and infused with cold saline at 2 temperatures, $4^{\circ}$ or $24^{\circ} \mathrm{C}$, over a period of 10 minutes. These rats were compared with those from a normal control group. Significant reductions in brain temperatures were achieved in both groups. No outcome measures were studied. The authors suggested further 


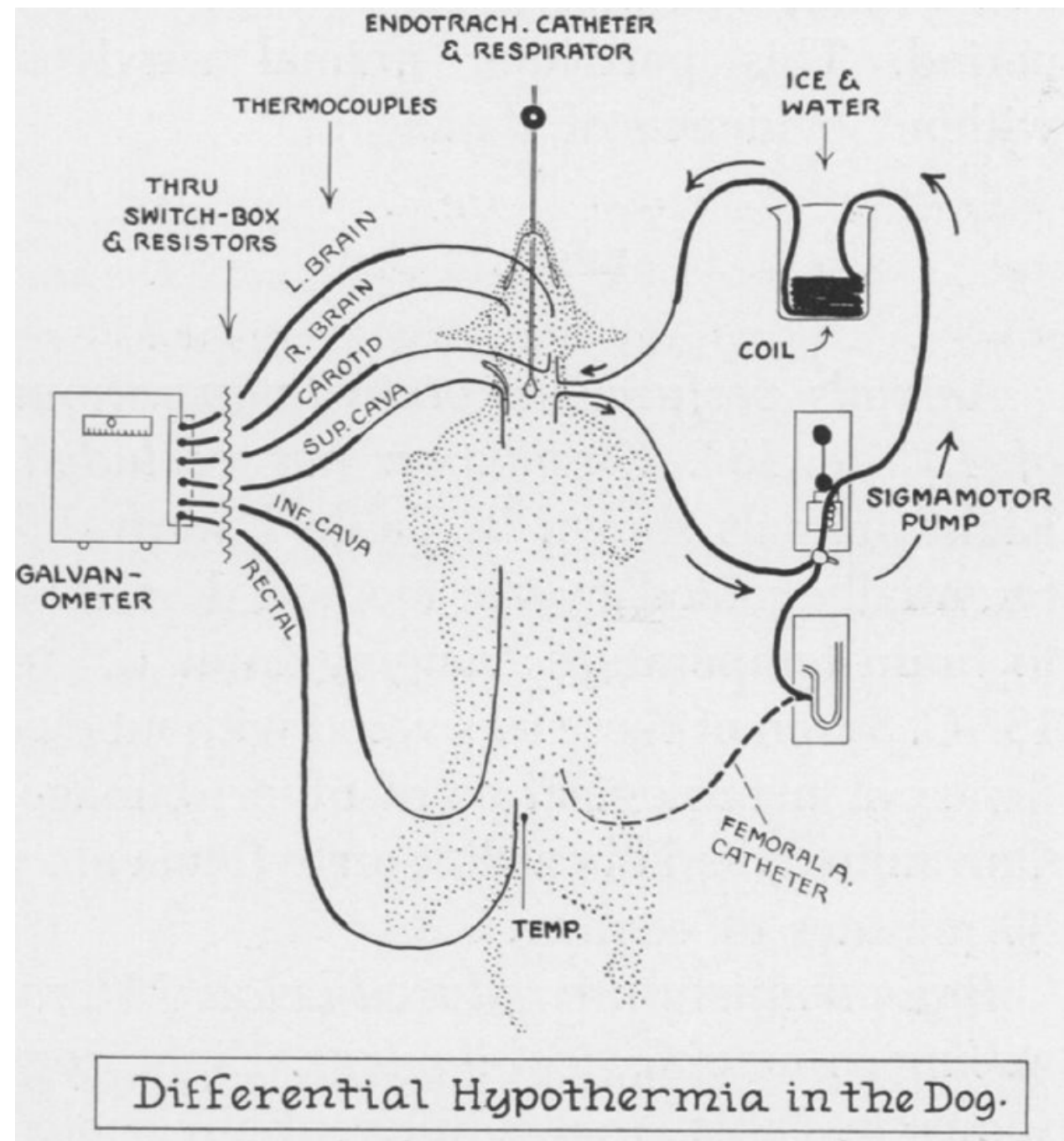

FIG. 3. Diagram showing hypothermia in a dog. Dogs were subjected to a period of complete circulatory occlusion, during which blood was drawn from the carotid artery, cooled extracorporeally, and reinfused to the carotid artery. A.= artery; ENDOTRACH. = endotracheal; INF. = inferior; L. = left; R. = right; SUP. = superior; TEMP. = temperature. Reprinted with permission from Parkins et al: Annals of Surgery 140:284-289, 1954, Lippincott Williams \& Wilkins, Inc.

studies of shock models in animals, followed by potential clinical trials in humans.

To date, endovascular methods of selective cerebral hypothermia remain in the experimental phase. The safety of this method as a primary intervention for TBI remains to be determined. The feasibility of emergency carotid artery infusion, especially with hemodilution, remains unlikely at this time in patients with polytrauma. Hypothermic retrograde jugular flush appears to be an effective means of achieving rapid preferential hypothermia, although it is associated with increases in cerebral blood flow. ${ }^{43}$ Conflicts regarding ICP dynamics and rates of thrombocytopenia or coagulopathy in conjunction with endovascular methods of selective hypothermia remain to be studied but may pose significant limitations in patients with TBI.

\section{Extraluminal Vascular Cooling}

The novel method of extraluminal vascular cooling was recently developed by the Walter Reed Army Institute of Research and involves a cooling cuff containing cold circulating water wrapped around the common carotid arteries. In a model of MCA occlusion in rats, extraluminal vascular cooling of the common carotid arteries was performed starting 30 minutes postinjury and was maintained for 90 minutes. ${ }^{42}$ Brain temperatures were reduced by $2-5^{\circ} \mathrm{C}$ within 20 minutes, whereas the systemic temperature was maintained at $37^{\circ} \mathrm{C}$. No cardiovascular complications occurred. The authors were able to demonstrate decreases in infarct size in the MCA territory and diminished rates of periinfarct depolarizations in the treatment group.

\section{Epidural Cooling}

Epidural brain cooling is another recently described method of achieving selective hypothermia. In a study by Cheng et al., ${ }^{6}$ cold saline $\left(4^{\circ} \mathrm{C}\right)$ was infused into the epidural space of swine via a double-lumen catheter. 


\section{E. Christian et al.}

Brain (deep and surface), epidural, and systemic temperatures were monitored, and cold saline infusion rates were manipulated to achieve target brain temperatures. Epidural pressures were also monitored. Surface brain temperatures were reduced to $17.3-21.6^{\circ} \mathrm{C}$ within $1 \mathrm{~min}$ ute, whereas deep brain temperatures were reduced to 27.2-29.7 within 5 minutes. Systemic temperatures were maintained during 6 hours of treatment. No hemodynamic or hematological complications were associated with this treatment, and ICPs remained stable.

In a separate study, the same author group assessed the efficacy of the epidural cooling method used in swine 1 hour after complete MCA occlusion and maintained for a period of 5 hours. ${ }^{45}$ Brain temperature was reduced to $<$ $30^{\circ} \mathrm{C}$ (deep brain) and $<20^{\circ} \mathrm{C}$ (brain surface), again with no changes in systemic temperature. The study showed a significantly decreased infarction volume $(<50 \%)$ with the cooling method as compared with the control group. Epidural cerebral cooling appears to offer a potent neuroprotective benefit, but to date this method has only been attempted in animal studies.

\section{Discussion}

Although a large multicenter RCT by Clifton et al. ${ }^{8}$ did not demonstrate an overall benefit of hypothermia in severe TBI, subsequent clinical trial data have suggested that systemic methods of inducing hypothermia provide effective control of ICP and cerebral perfusion pressure, as well as improvements in neurological outcome. ${ }^{15} \mathrm{Sev}-$ eral meta-analyses have attempted to reconcile the results from more than 25 clinical studies in which systemic hypothermia was assessed over the past 2 decades. ${ }^{24,28,31}$ McIntyre and colleagues ${ }^{28}$ published a systematic review of 12 trials on therapeutic hypothermia with results demonstrating an overall beneficial effect of moderate hypothermia $\left(32-33^{\circ} \mathrm{C}\right)$ in severe TBI. They reported a $19 \%$ relative reduction in deaths and a $22 \%$ relative reduction in poor neurological outcomes in comparison with normothermia. The review indicated that therapy should be conducted for at least 24 hours, with temperatures ranging between $32^{\circ}$ and $33^{\circ} \mathrm{C}$ and a rewarming period of $<$ 24 hours. Peterson and associates ${ }^{31}$ conducted a systematic review and meta-analysis and concluded that there was a significant reduction in deaths in the hypothermia group, although outcomes were influenced by variations in the induction method. It is likely that systemic hypothermia confers some neuroprotective effect, yet its benefits are potentially offset by the added risks incurred in patients with polytrauma. For instance, the relative risk of pneumonia associated with hypothermia according to one meta-analysis was 2.37 (95\% confidence interval 1.37-4.10). ${ }^{20}$ In another study, authors reported an increased rate of thrombocytopenia following hypothermic management, with associated unfavorable neurological

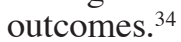

In response to the systemic risks revealed by these studies, investigators have recently pursued more selective methods of brain cooling. The same principles that have been shown to increase the efficacy of systemic hypothermia are maintained for regional methods as well.
For instance, authors of prior studies have determined that hypothermic interventions following longer delays are less efficacious. ${ }^{5,9,11,27}$ Moreover, prolonged treatment with hypothermia (12-48 hours) showed longer lasting neuroprotective benefits than shorter periods of therapy. ${ }^{10-12}$ Another important principle established by previous authors is that brain temperature should be maintained at $\leq 34^{\circ} \mathrm{C}$ for the duration of therapy..$^{18,37}$ These guidelines suggest that the extent and duration of cooling, as well as the induction time, are likely to affect outcomes and should play a central role in guiding the development and research of regional hypothermic methods. Furthermore, in the case of selective hypothermia, maintaining the brain-body gradient is of paramount importance.

Proponents of the cooling helmet point to the feasibility of its use by emergency personnel in the field, yet outcome benefits and costs associated with this therapy still need to be analyzed. ${ }^{41}$ Based on the limited studies available, the intranasal method can be used to reach the target hypothermic zone in less time than the helmet (15 minutes vs 3.4 hours). ${ }^{41,44}$ Potential concerns regarding the uneven distribution of cooling of various brain regions have been reported in association with some regional methods, including surface, epidural, and intranasal cooling. ${ }^{6,23}$ On the other hand, endovascular cooling and extraluminal cuffs have been shown to provide uniform cooling of the brain. ${ }^{42}$

\section{Conclusions}

Selective methods of cerebral hypothermia remain a viable option for neuroprotective therapy in patients that have sustained TBI. To date, surface cooling methods and intranasal cooling systems are the only types of selective hypothermia that have been tested in humans following TBI, whereas endovascular, extraluminal, and epidural cooling methods have been tested only in animal models and patients with stroke. Studies in which authors compare and possibly combine several methods may be indicated in the future. For now, the least invasive and most selective methods of hypothermia hold the greatest promise in becoming practical measures for providing neuroprotection following TBI. Further prospective research is clearly indicated to delineate the risks and benefits associated with these new therapies.

\section{Disclosure}

The authors do not report any conflict of interest concerning the materials or methods used in this study or the findings specified in this paper.

\section{References}

1. Andrews PJ, Harris B, Murray GD: Randomized controlled trial of effects of the airflow through the upper respiratory tract of intubated brain-injured patients on brain temperature and selective brain cooling. Br J Anaesth 94:330-335, 2005

2. Barone FC, Feuerstein GZ, White RF: Brain cooling during transient focal ischemia provides complete neuroprotection. Neurosci Biobehav Rev 21:31-44, 1997

3. Bayir H, Clark RS, Kochanek PM: Promising strategies to minimize secondary brain injury after head trauma. Crit 
Care Med 31:S112-S117, 2003

4. Brain Trauma Foundation, American Association of Neurological Surgeons, Congress of Neurological Surgeons, Joint Section on Neurotrauma and Critical Care, AANS/CNS, Bratton SL, et al: Guidelines for the management of severe traumatic brain injury. III. Prophylactic hypothermia. J Neurotrauma 24 (1 Suppl):S21-S25, 2007

5. Carroll M, Beek O: Protection against hippocampal CA1 cell loss by post-ischemic hypothermia is dependent on delay of initiation and duration. Metab Brain Dis 7:45-50, 1992

6. Cheng H, Shi J, Zhang L, Zhang Q, Yin H, Wang L: Epidural cooling for selective brain hypothermia in porcine model. Acta Neurochir (Wien) 148:559-564, 2006

7. Clifton GL, Jiang JY, Lyeth BG, Jenkins LW, Hamm RJ, Hayes RL: Marked protection by moderate hypothermia after experimental traumatic brain injury. J Cereb Blood Flow Metab 11:114-121, 1991

8. Clifton GL, Miller ER, Choi SC, Levin HS, McCauley S, Smith KR Jr, et al: Lack of effect of induction of hypothermia after acute brain injury. N Engl J Med 344:556-563, 2001

9. Coimbra C, Wieloch T: Moderate hypothermia mitigates neuronal damage in the rat brain when initiated several hours following transient cerebral ischemia. Acta Neuropathol 87:325-331, 1994

10. Colbourne F, Corbett D: Delayed and prolonged post-ischemic hypothermia is neuroprotective in the gerbil. Brain Res 654:265-272, 1994

11. Colbourne F, Corbett D: Delayed postischemic hypothermia: a six month survival study using behavioral and histological assessments of neuroprotection. J Neurosci 15:7250-7260, 1995

12. Corbett D, Hamilton M, Colbourne F: Persistent neuroprotection with prolonged postischemic hypothermia in adult rats subjected to transient middle cerebral artery occlusion. Exp Neurol 163:200-206, 2000

13. Covaciu L, Allers M, Enblad P, Lunderquist A, Wieloch T, Rubertsson S: Intranasal selective brain cooling in pigs. Resuscitation 76:83-88, 2008

14. Ehrlich MP, McCullough JN, Zhang N, Weisz DJ, Juvonen T, Bodian CA, et al: Effect of hypothermia on cerebral blood flow and metabolism in the pig. Ann Thorac Surg 73:191197,2002

15. Gal R, Cundrle I, Zimova I, Smrcka M: Mild hypothermia therapy for patients with severe brain injury. Clin Neurol Neurosurg 104:318-321, 2002

16. Ginsberg MD, Sternau LL, Globus MY, Dietrich WD, Busto $\mathrm{R}$ : Therapeutic modulation of brain temperature: relevance to ischemic brain injury. Cerebrovasc Brain Metab Rev 4:189-225, 1992

17. Gluckman PD, Wyatt JS, Azzopardi D, Ballard R, Edwards $\mathrm{AD}$, Ferriero DM, et al: Selective head cooling with mild systemic hypothermia after neonatal encephalopathy: multicentre randomised trial. Lancet 365:663-670, 2005

18. Gunn AJ, Gunn TR, de Haan HH, Williams CE, Gluckman PD: Dramatic neuronal rescue with prolonged selective head cooling after ischemia in fetal lambs. J Clin Invest 99:248256, 1997

19. Harris BA, Andrews PJ, Murray GD: Enhanced upper respiratory tract airflow and head fanning reduce brain temperature in brain-injured, mechanically ventilated patients: a randomized, crossover, factorial trial. Br J Anaesth 98:93-99, 2007

20. Henderson WR, Dhingra VK, Chittock DR, Fenwick JC, Ronco JJ: Hypothermia in the management of traumatic brain injury. A systematic review and meta-analysis. Intensive Care Med 29:1637-1644, 2003

21. Jiang JY, Xu W, Li WP, Gao GY, Bao YH, Liang YM, et al: Effect of long-term mild hypothermia or short-term mild hypothermia on outcome of patients with severe traumatic brain injury. J Cereb Blood Flow Metab 26:771-776, 2006
22. Jiang JY, Xu W, Yang PF, Gao GY, Gao YG, Liang YM, et al: Marked protection by selective cerebral profound hypothermia after complete cerebral ischemia in primates. J Neurotrauma 23:1847-1856, 2006

23. Jordan JD, Carhuapoma JR: Hypothermia: comparing technology. J Neurol Sci 261:35-38, 2007

24. Kochanek PM, Safar PJ: Therapeutic hypothermia for severe traumatic brain injury. JAMA 289:3007-3009, 2003

25. Liu WG, Qiu WS, Zhang Y, Wang WM, Lu F, Yang XF: Effects of selective brain cooling in patients with severe traumatic brain injury: a preliminary study. J Int Med Res 34: 58-64, 2006

26. Maier CM, Sun GH, Cheng D, Yenari MA, Chan PH, Steinberg GK: Effects of mild hypothermia on superoxide anion production, superoxide dismutase expression, and activity following transient focal cerebral ischemia. Neurobiol Dis 11:28-42, 2002

27. Markgraf CG, Clifton GL, Moody MR: Treatment window for hypothermia in brain injury. J Neurosurg 95:979-983, 2001

28. McIntyre LA, Fergusson DA, Hebert PC, Moher D, Hutchison JS: Prolonged therapeutic hypothermia after traumatic brain injury in adults: a systematic review. JAMA 289:2992-2999, 2003

29. Ohta T, Sakaguchi I, Dong LW, Nagasawa S, Yasuda A: Selective cooling of brain using profound hemodilution in dogs. Neurosurgery 31:1049-1054, 1992

30. Parkins WM, Jensen JM, Vars HM: Brain cooling in the prevention of brain damage during periods of circulatory occlusion in dogs. Ann Surg 140:284-289, 1954

31. Peterson K, Carson S, Carney N: Hypothermia treatment for traumatic brain injury: a systematic review and meta-analysis. J Neurotrauma 25:62-71, 2008

32. Phelps C: Traumatic injuries of the brain and its membranes. New York, NY: D. Appleton \& Co, 1897

33. Qiu W, Shen H, Zhang Y, Wang W, Liu W, Jiang Q, et al: Noninvasive selective brain cooling by head and neck cooling is protective in severe traumatic brain injury. J Clin Neurosci 13:995-1000, 2006

34. Qiu WS, Wang WM, Du HY, Liu WG, Shen H, Shen LF, et al: Thrombocytopenia after therapeutic hypothermia in severe traumatic brain injury. Chin J Traumatol 9:238-241, 2006

35. Schmitt FC, Buchheim K, Meierkord H, Holtkamp M: Anticonvulsant properties of hypothermia in experimental status epilepticus. Neurobiol Dis 23:689-696, 2006

36. Schwartz AE, Stone JG, Finck AD, Sandhu AA, Mongero LB, Adams DC, et al: Isolated cerebral hypothermia by single carotid artery perfusion of extracorporeally cooled blood in baboons. Neurosurgery 39:577-572, 1996

37. Takeda Y, Namba K, Higuchi T, Hagioka S, Takata K, Hirakawa M, et al: Quantitative evaluation of the neuroprotective effects of hypothermia ranging from 34 degrees $\mathrm{C}$ to 31 degrees $\mathrm{C}$ on brain ischemia in gerbils and determination of the mechanism of neuroprotection. Crit Care Med 31:255-260, 2003

38. Thurman DJ, Alverson C, Dunn KA, Guerrero J, Sniezek JE: Traumatic brain injury in the United States: a public health perspective. J Head Trauma Rehabil 14:602-615, 1999

39. Tsai MS, Barbut D, Tang W, Wang H, Guan J, Wang T, et al: Rapid head cooling initiated coincident with cardiopulmonary resuscitation improves success of defibrillation and post-resuscitation myocardial function in a porcine model of prolonged cardiac arrest. J Am Coll Cardiol 51:1988-1990, 2008

40. Wang GJ, Deng HY, Maier CM, Sun GH, Yenari MA: Mild hypothermia reduces ICAM-1 expression, neutrophil infiltration and microglia/monocyte accumulation following experimental stroke. Neuroscience 114:10811090, 2002

41. Wang H, Olivero W, Lanzino G, Elkins W, Rose J, Honings D, 


\section{E. Christian et al.}

et al: Rapid and selective cerebral hypothermia achieved using a cooling helmet. J Neurosurg 100:272-277, 2004

42. Wei G, Hartings JA, Yang X, Tortella FC, Lu XC: Extraluminal cooling of bilateral common carotid arteries as a method to achieve selective brain cooling for neuroprotection. J Neurotrauma 25:549-559, 2008

43. Wen YS, Huang MS, Lin MT, Lee CH: Rapid brain cooling by hypothermic retrograde jugular vein flush. J Trauma 58:577-581, 2005

44. Wolfson MR, Malone DJ, Wu J, Hoffman J, Rozenberg A, Shaffer TH, et al: Intranasal perfluorochemical spray for preferential brain cooling in sheep. Neurocrit Care 8:437-447, 2008
45. Zhang L, Cheng H, Shi J, Chen J: Focal epidural cooling reduces the infarction volume of permanent middle cerebral artery occlusion in swine. Surg Neurol 67:117-121, 2007

Manuscript submitted June 15, 2008.

Accepted July 31, 2008.

Address correspondence to: Gabriel Zada, M.D., Department of Neurosurgery, University of Southern California, 1200 North State Street, Suite 5046, Los Angeles, California 90089. email: gzada@ usc.edu. 